\title{
Physiologic and Neuropathologic Aspects of Hypothermic Circulatory Arrest in Newborn Dogs
}

\author{
DENNIS J. MUJSCE, JAVAD TOWFIGHI, AND ROBERT C. VANNUCCI \\ Departments of Pediatrics (Neonatology [D.J.M.] and Neurology [R.C.V.]) and Pathology (Neuropathology \\ [J.T.]), The Pennsylvania State University College of Medicine, The Milton S. Hershey Medical Center, \\ Hershey, Pennsylvania 17033
}

\begin{abstract}
A model of hypothermic circulatory arrest has been developed in the newborn dog. Ten puppies were anesthetized with halothane, paralyzed, and artificially ventilated with $70 \%$ nitrous oxide $30 \%$ oxygen to arterial oxygen pressure $>8.0 \mathrm{kPa}(60 \mathrm{~mm} \mathrm{Hg})$, arterial carbon dioxide pressure of $4.4-5.6 \mathrm{kPa}(33-42 \mathrm{~mm} \mathrm{Hg})$, and arterial pH of 7.35-7.42. Animals were surface cooled to $20^{\circ} \mathrm{C}$, after which cardiac arrest was produced with i.v. KCl. Dogs remained asystolic without ventilation for $\mathbf{1 . 0}$ $(n=4), 1.5(n=3)$, or $2.0(n=3)$ h. Resuscitation was accomplished with closed-chest compression, mechanical ventilation, i.v. epinephrine and $\mathrm{NaHCO}_{3}$, and rewarming to $37^{\circ} \mathrm{C}$. Postarrest recovery was maintained for $3-4 \mathrm{~h}$; thereafter, the puppies underwent perfusion-fixation of their brains for pathologic analysis. Plasma glucose (control $=8.3 \mathrm{mmol} / \mathrm{L}$ ) increased slightly during hypothermic cardiac arrest $(+36 \%)$ but was markedly elevated at 15 min postarrest $(20 \mathrm{mmol} / \mathrm{L})$. Blood lactate $($ control $=1.1$ $\mathrm{mmol} / \mathrm{L}$ ) increased almost $\mathbf{2 0 0 \%}$ during hypothermic circulatory arrest, with a further rise to $9.0 \mathrm{mmol} / \mathrm{L}$ at 15 min postarrest. Thereafter, lactate decreased in the 1-h arrested dogs but increased progressively in the other groups. Mean arterial blood pressure returned to baseline $(73 \mathrm{~mm} \mathrm{Hg}$ ) by 15 min postarrest, remained stable in the 1-h dogs, but fell at $3 \mathrm{~h}$ to 62 and $34 \mathrm{~mm} \mathrm{Hg}$ in the 1.5and 2.0 -h groups, respectively. No neuropathologic alterations were seen in puppies arrested for $1 \mathrm{~h}$, whereas all puppies arrested for 1.5 or $2 \mathrm{~h}$ had varying degrees of cerebral cortical and hippocampal damage. Thus, newborn dogs tolerate $1 \mathrm{~h}$ of hypothermic circulatory arrest without brain damage, with graded neuronal injury thereafter. The experimental model has direct clinical relevance and can be used to study mechanisms of cellular injury in brain, heart, and other organs during prolonged ischemia. (Pediatr Res 28: 354-360, 1990)
\end{abstract}

\section{Abbreviations}

$\mathrm{PaO}_{2}$, arterial oxygen pressure

$\mathrm{PaCO}_{2}$, arterial carbon dioxide pressure

pHa, arterial pH

FAM, formaldehyde glacial acetic acid-absolute methanol

Hypothermic circulatory arrest has become an established procedure for the operative correction of congenital heart defects

Received January 1, 1990; accepted May 10, 1990.

Correspondence: Robert C. Vannucci, M.D., Department of Pediatrics, The Milton S. Hershey Medical Center, P.O. Box 850, Hershey, PA 17033 in infants and children. The rationale for this surgical approach relates to the well-known observation that acute brain damage secondary to systemic hypoxia, hypotension, or cardiac arrest is prevented or at least substantially reduced by prior or concurrent hypothermia (1-5). It is the duration of cardiac arrest and its attendant total cerebral ischemia that is limiting for the prevention of brain damage. It is not known how long an infant can tolerate hypothermic circulatory arrest without sustaining ischemic brain injury, although clinical practice suggests a "safe" interval of $60-70 \mathrm{~min}(6-8)$. Unfortunately, infants occasionally sustain brain damage even when the duration of cardiac arrest is well within the "therapeutic window" $(9,10)$. It has not been established whether such brain damage arises as a silent complication of the surgical procedure itself (e.g. postoperative hypotension, air emboli, etc.) or as a result of cerebral ischemia beyond the safety margin for any specific individual infant. Given the fact that $0.5-1.0 \%$ of all infants are born with surgically correctable cardiac defects, it is surprising that little research has been conducted in developing animals to answer clinically relevant questions regarding hypothermic circulatory arrest. Accordingly, we have developed a model of hypothermic circulatory arrest in the newborn dog and have characterized the systemic physiologic and metabolic alterations that occur during the course of cardiac arrest and after resuscitation. In addition, neuropathologic alterations have been determined in relation to the duration of total cerebral ischemia.

\section{MATERIALS AND METHODS}

Animal preparation. Pregnant mongrel dogs were purchased from a local breeder and housed in individual kennels. After spontaneous vaginal delivery, the newborn puppies were kept with the bitches until time of experimental manipulation at 2-8 d postnatal age. Each puppy initially was anesthetized with $4 \%$ halothane, rapidly tracheostomized, paralyzed with pancuronium bromide $(1.0 \mathrm{mg} / \mathrm{kg} \mathrm{s.c.})$, and artificially ventilated with a gas mixture of $70 \% \mathrm{~N}_{2} \mathrm{O} 30 \% \mathrm{O}_{2}$. Duration of the halothane exposure never exceeded $10 \mathrm{~min}$. Under local anesthesia $(1 \%$ procaine $\mathrm{HCl}$ ), a femoral artery was cannulated with polyethylene tubing (PE-50), which was connected via a Statham transducer (Gould, Inc., Oxnard, CA) to a dynographic recorder (model R 711; Beckman Instruments, Inc., Fullerton, CA) to monitor systemic heart rate and blood pressure. A side arm of the catheter allowed for intermittent collection $(0.2 \mathrm{~mL})$ of arterial blood for analysis of oxygen and acid-base status on a micro-blood gas analyzer (model ABL 30; Radiometer America Inc., Westlake, $\mathrm{OH}$ ). Oxygen and acid-base balance were maintained within a narrow range $\left[\mathrm{PaCO}_{2}: 4.4-5.6 \mathrm{kPa}(33-42 \mathrm{~mm}\right.$ $\mathrm{Hg})$; pHa: $\left.7.35-7.42 ; \mathrm{PaO}_{2}>8.0 \mathrm{kPa}(60 \mathrm{~mm} \mathrm{Hg})\right]$ by frequent adjustments of tidal volume $( \pm 1 \mathrm{~mL} / 100 \mathrm{~g}$ body $\mathrm{wt})$ and ventilatory rate ( \pm 50 breaths/min). A femoral vein also was cannu- 
lated as an access route for infusion of fluids and injection of drugs. Body temperature initially was maintained at $37 \pm 0.2^{\circ} \mathrm{C}$ by means of rectal probe attached to a servo-controlled heating lamp.

Induction of hypothermia. Once steady-state arterial normoxia and acid-base balance were achieved, the newborn dogs were gently positioned prone on a plastic bag containing crushed ice, and additional ice packs were applied to the back and head. Rectal temperature was continuously monitored during the cooling period, and the ice packs removed when the temperature approached $20^{\circ} \mathrm{C}$. No adjustments in tidal volume or ventilatory rate were made during or after the cooling process. Rectal temperature was maintained between 20 and $21^{\circ} \mathrm{C}$ by occasionally applying ice packs to the lateral aspects of the chest and abdomen.

Circulatory arrest and resuscitation. Once hypothermia to a core (rectal) temperature of $20^{\circ} \mathrm{C}$ was achieved, the heart of each newborn dog was arrested by the i.v. administration of $\mathrm{KCl}(25$ $\mathrm{mmol} / \mathrm{L})$ in a small volume $(2-3 \mathrm{~mL})$. Artificial ventilation was discontinued simultaneous with the cardiac arrest. Complete circulatory arrest was verified by the absence of spontaneous heart rate or systemic blood pressure monitored on the dynograph. The animals remained asystolic for either $1.0(n=4), 1.5$ $(n=3)$, or $2.0(n=3) \mathrm{h}$. Thereafter, all animals were successfully resuscitated by: 1) resumption of artificial ventilation with $70 \%$ $\mathrm{N}_{2} \mathrm{O} 30 \% \mathrm{O}_{2}$ at $1.5 \times$ the prearrest rate without change in tidal volume; 2) body warming with a heating lamp; 3) i.v. injection of $\left.\mathrm{NaHCO}_{3}(2.0 \mathrm{mmol} / \mathrm{kg}) ; 4\right)$ i.v. injection of $1 / 10000$ epinephrine $(0.2 \mathrm{~mL} / \mathrm{kg}) ; 5)$ i.v. injection of $10 \%$ calcium gluconate $(1.0 \mathrm{~mL} / \mathrm{kg})$; and 6) closed chest cardiac massage. These maneuvers resulted in spontaneous heart action in all animals within $10 \mathrm{~min}$, with progressively increasing heart rate and systemic blood pressure thereafter. After the initial surge in heart rate and blood pressure, any subsequent decrease in blood pressure $(<2 / 3$ baseline value) was treated with a constant infusion of dopamine in a dosage ranging from 2 to $24 \mu \mathrm{g} / \mathrm{kg} / \mathrm{min}$. Plasma glucose, hematocrit, arterial oxygen, and acid-base status were determined every 15 min during recovery. Hypoglycemia (blood glucose $<4.5 \mathrm{mmol} / \mathrm{L}$ ) was treated with a constant but variable infusion of $5-10 \%$ glucose in water to maintain plasma glucose concentrations between 4.5 and $10.0 \mathrm{mmol} / \mathrm{L}$. Metabolic acidosis $(\mathrm{pHa}$ $<7.25)$ was treated with bolus injections of $\mathrm{NaHCO}_{3}(1.0 \mathrm{mmol} /$ $\mathrm{kg})$. Hypocapnia $\left[\mathrm{PaCO}_{2}<3.3 \mathrm{kPa}(25 \mathrm{~mm} \mathrm{Hg})\right]$ was corrected by adjustments in ventilatory rate or tidal volume. The animals were maintained for 3-4 h, at which time they underwent perfusion-fixation of their brains.

Two paralyzed and artifically ventilated newborn dogs served as controls. One was maintained at $37^{\circ} \mathrm{C}$ for $6 \mathrm{~h}$, and the other was rendered hypothermic to $20^{\circ} \mathrm{C}$ for $1 \mathrm{~h}$ followed by rewarming to $37^{\circ} \mathrm{C}$. Neither animal underwent circulatory arrest.

Neuropathologic methods. After 3-4 h of recovery from hypothermic circulatory arrest, each newborn dog was deeply anesthetized with pentobarbital ( $50 \mathrm{mg} / \mathrm{kg}$ i.v.), at which time they underwent perfusion-fixation of their brains with FAM 1:1:8. The calvaria were removed and the brains left in situ in FAM for $24 \mathrm{~h}$, after which they were removed from the skulls and examined grossly for abnormalities. Each FAM-fixed brain then was sectioned in the coronal plane and blocks 2- to 3-mm thick through the entire brain were embedded in paraffin. Sections $5-$ to $6-\mu \mathrm{m}$ thick were stained with hematoxylin and eosin and with acid fuchsin-cresyl violet. The stained tissue sections then were examined blindly at the light microscopic level.

Statistical analyses. Statistical analysis of the data was accomplished using one-way analysis of variance and analysis of variance for sequential data.

Institutional approval. The experiments described here were reviewed by the Animal Care and Use Committee of The Milton S. Hershey Medical Center, The Pennsylvania State University, and approved on August 8, 1987.

\section{RESULTS}

Systemic physiologic variables. A total of 10 newborn dogs underwent the procedures necessary to produce hypothermic circulatory arrest with recovery. During hypothermia per se, mean arterial blood pressure and heart rate decreased to 70 and $31 \%$ of the normothermic values, respectively $(p<0.001)$ (Fig. 1). $\mathrm{PaCO}_{2}$ and $\mathrm{pHa}$ were unchanged from control (Fig. 2), whereas $\mathrm{PaO}_{2}$ was increased by $34 \%$ (not shown); $\mathrm{PaCO}_{2}, \mathrm{PaO}_{2}$, and $\mathrm{pHa}$ were measured at $37^{\circ} \mathrm{C}$ (11). Plasma glucose increased slightly $(+23 \%)$ during hypothermia without a concurrent change in blood lactate (Fig. 3).

No puppy exhibited spontaneous heart rate or blood pressure during the course of hypothermic circulatory arrest $(1-2 h)$. Sampling of stagnant arterial blood immediately before resuscitation revealed that $\mathrm{pHa}$ had decreased to 7.1 or lower, reflecting predominantly a respiratory acidosis most severe in the single 2 $\mathrm{h}$ arrested animal in which blood could be collected (Figs. 2 and 3). Plasma glucose was unchanged from prearrest, hypothermic concentrations, and blood lactate was only slightly increased (Fig. 3).

During recovery, systemic blood pressure increased to or above prearrest hypothermic values by $15 \mathrm{~min}$ after resuscitation and was not different from normothermic control values by $1 \mathrm{~h}$ (Fig. 1). Heart rate also returned to baseline by $1 \mathrm{~h}$, at which time all animals were near to or approaching a core temperature of $37^{\circ} \mathrm{C}$. Thereafter, all puppies required an infusion of dopamine in

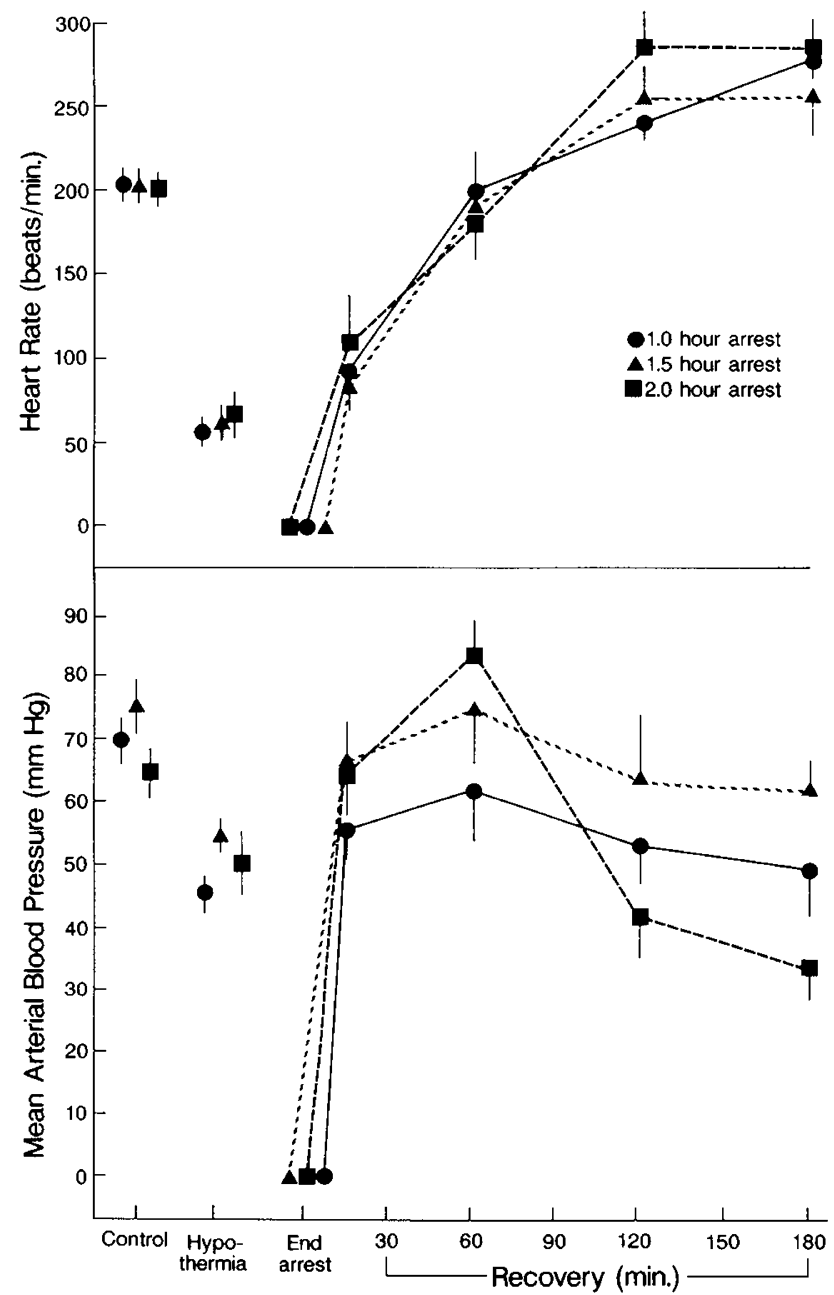

Fig. 1. Heart rate and blood pressure before, during, and after hypothermic circulatory arrest in newborn dogs. Control and hypothermia symbols represent means of 10 newborn dogs, whereas the symbols at end-arrest and during recovery represent four (1-h arrest), three (1.5-h arrest), or three (2.0-h arrest) animals. Vertical lines denote \pm 1 SEM. 


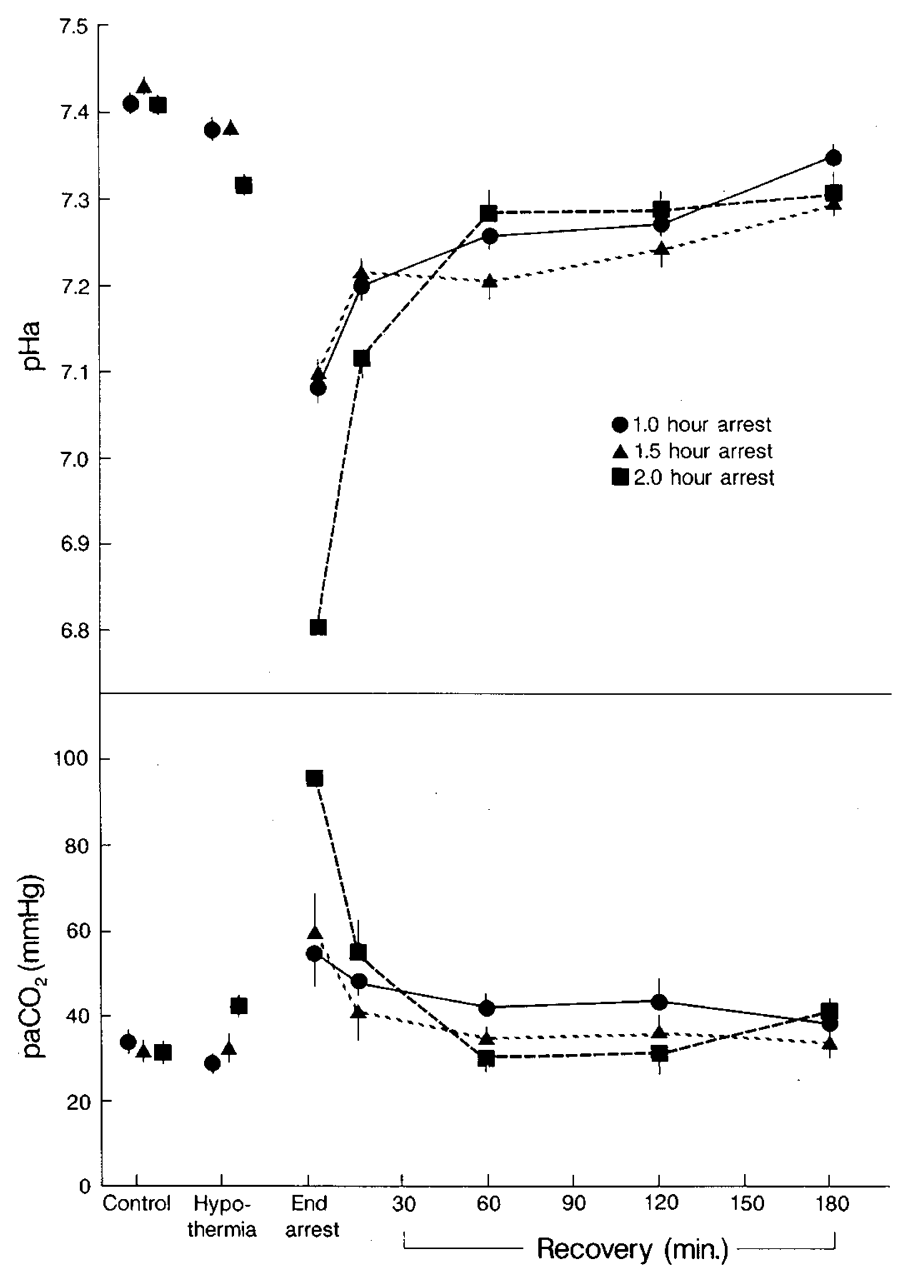

Fig. 2. pHa and $\mathrm{PaCO}_{2}$ before, during, and after hypothermic circulatory arrest in newborn dogs. Control and hypothermia symbols represent means of 10 newborn dogs, whereas the symbols at end-arrest and during recovery represent four ( 1 -h arrest), three (1.5-h arrest), or three (2.0-h arrest) animals. The end-arrest symbol for the 2.0 - $\mathrm{h}$ animals represents a single value. Vertical lines denote \pm 1 SEM. S.I. conversion unit for $\mathrm{PaCO}_{2}: \mathrm{kPa}=\mathrm{mm} \mathrm{Hg} \times 0.133$.

varying concentrations to maintain their respective blood pressures at or above $67 \%$ of control. Despite the pressor infusion, a decrease in blood pressure occurred in the 2-h arrested animals to $55 \%$ of normothermic, prearrest pressure (see also Table 1).

After resuscitation, plasma glucose essentially doubled in all animals at $15 \mathrm{~min}$ of recovery, thereafter decreasing to or below the baseline concentration (Fig. 3). Intravenous glucose infusions were required to maintain plasma glucose levels above $4.5 \mathrm{mmol} /$ $\mathrm{L}$ in 8 of 10 puppies. Blood lactate followed the early increase in plasma glucose, such that by 15 min of recovery, the metabolite had increased 8 -fold above the prearrest hypothermic value $(1.1$ $\mathrm{mmol} / \mathrm{L})$ and nearly 2 -fold above the end-arrest value (3.2 $\mathrm{mmol} / \mathrm{L}$ ). Thereafter, blood lactate decreased toward the baseline in the $1-h$ arrested animals but increased progressively in the other two groups, especially in the 2-h arrested puppies (Table 1).

At $15 \mathrm{~min}$ of recovery, $\mathrm{pHa}$ was already partially corrected, owing largely to a reversal of the prior hypercapnia with resumption of artificial ventilation (Fig. 2). Thereafter, pHa continued to normalize such that by $3 \mathrm{~h}$ of recovery, all animals but one exhibited a value above 7.26. A single 2-h arrested puppy (no. 8) showed a pHa of 7.13 at $3 \mathrm{~h}$ of recovery, concurrent with a $\mathrm{PaCO}_{2}$ of $5.1 \mathrm{kPa}(38 \mathrm{~mm} \mathrm{Hg})$ and blood lactate of $20 \mathrm{mmol} / \mathrm{L}$ (Table 1).

Neuropathologic findings. The macroscopic appearance of all

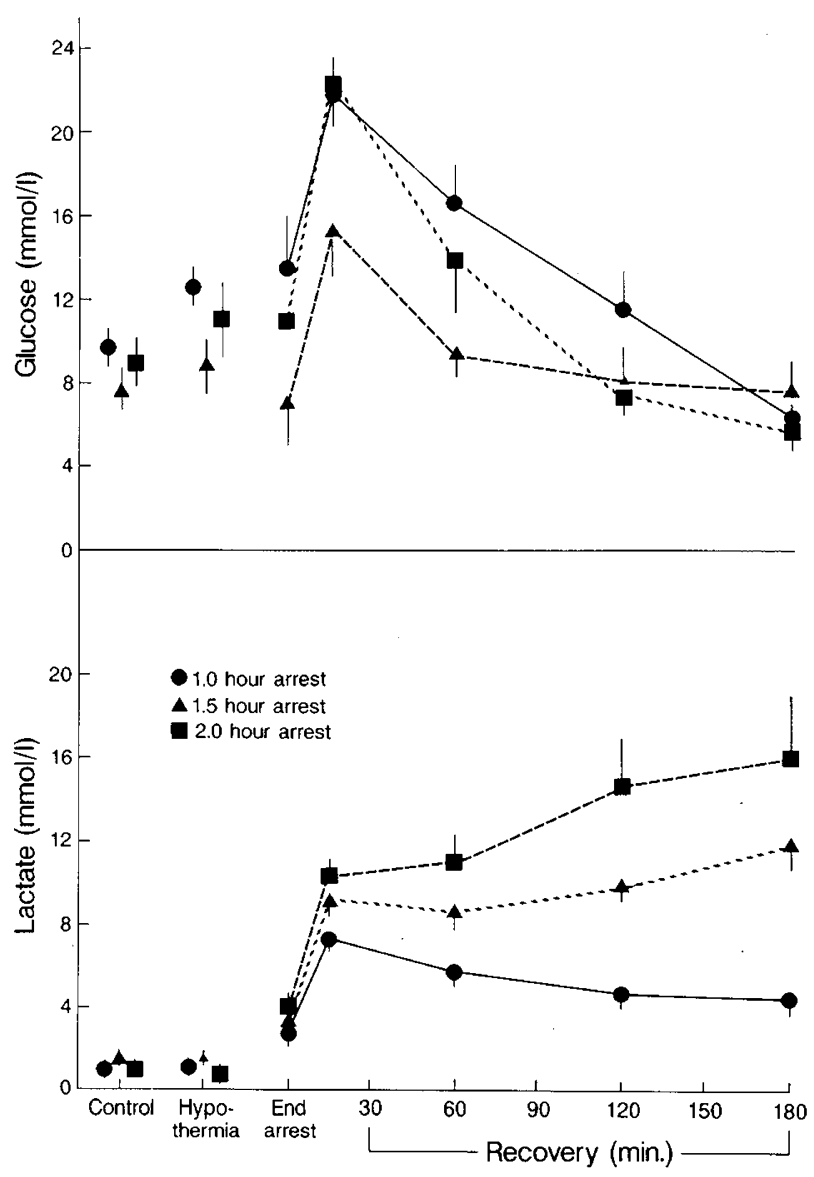

Fig. 3. Plasma glucose and blood lactate before, during, and after hypothermic circulatory arrest in newborn dogs. Control and hypothermia symbols represent means of 10 newborn dogs, whereas the symbols at end-arrest and during recovery represent four (1-h arrest), three (1.5-h arrest), or three (2.0-h arrest) animals. The end-arrest symbol for the 2.0 $\mathrm{h}$ animals represents a single value. Vertical lines denote \pm 1 SEM.

brains, including those of the two control animals, was normal. There were no histologic alterations in gray or white matter in the brains of the control animals or of the four animals subjected to $1 \mathrm{~h}$ of circulatory arrest (Table 2). All animals subjected to 1.5 and $2.0 \mathrm{~h}$ of hypothermic cardiac arrest exhibited brain damage limited to gray matter structures of the cerebral hemispheres. No white matter alterations were seen in any animal. Despite the short survival times (3-4 h), the process of ischemic cell change of neurons was well advanced. Tissue injury was characterized by selective necrosis of individual neurons that exhibited eosinophilic cytoplasm and either pyknotic or karyorrhexic nuclei (Fig. 4). Damage was localized predominantly in layers 3 and $5+6$ of cerebral cortex with occasional involvement of layers 2 and 4 as well. Patchy foci of selectively damaged neurons within cortex were more prominent in posterior than in anterior sections, with a distinct accentuation at the lateral and superior aspects of the cerebral hemispheres. In these most severely involved regions, damage was estimated as mild (up to $25 \%$ of neurons damaged), moderate $(26-50 \%$ of neurons damaged), or severe (majority of neurons involved with or without rarefaction of the neuropile). Examples of these graded changes are depicted in Figure 5. Damage within cerebral cortex was mild in the three animals subjected to $1.5 \mathrm{~h}$ of hypothermic circulatory arrest, whereas damage was moderate to severe in the three animals subjected to $2 \mathrm{~h}$ of circulatory arrest.

Ischemic neuronal alterations of other gray matter structures were absent in all animals subjected to $1.5 \mathrm{~h}$ of circulatory arrest despite the presence of damage within cerebral cortex. Two of the three animals subjected to $2 \mathrm{~h}$ of circulatory arrest exhibited 
Table 1. Systemic physiologic variables and therapy of individual newborn dogs during recovery from hypothermic circulatory arrest*

\begin{tabular}{|c|c|c|c|c|c|c|c|}
\hline \multirow[b]{2}{*}{ Animal } & \multicolumn{4}{|c|}{ Physiologic variables } & \multicolumn{3}{|c|}{ Therapy } \\
\hline & $\begin{array}{c}\text { Lowest blood } \\
\text { pressure }(\mathrm{mm} \mathrm{Hg})\end{array}$ & $\begin{array}{c}\text { Lowest plasma } \\
\text { glucose }(\mathrm{mmol} / \mathrm{L})\end{array}$ & $\begin{array}{c}\text { Highest blood } \\
\text { lactate }(\mathrm{mmol} / \mathrm{L})\end{array}$ & $\begin{array}{l}\text { Lowest } \\
\mathrm{pHa}\end{array}$ & $\begin{array}{l}\text { Glucose infusion } \\
(\mu \mathrm{g} / \mathrm{kg} / \mathrm{min})\end{array}$ & $\begin{array}{l}\text { Dopamine infusion } \\
(\mu \mathrm{g} / \mathrm{kg} / \mathrm{min})\end{array}$ & $\begin{array}{l}\text { Total } \mathrm{NaHCO}_{3} \\
(\mathrm{mmol})\end{array}$ \\
\hline \multicolumn{8}{|l|}{1.0 -h arrest } \\
\hline 1 & $52 / 40$ & 3.9 & 7.0 & 7.15 & 2.0 & 4.1 & 5.5 \\
\hline 2 & $44 / 36$ & 6.3 & 6.9 & 7.12 & 1.3 & 21.3 & 7.0 \\
\hline 3 & $68 / 58$ & 10.5 & 7.5 & 7.24 & & 11.5 & 8.0 \\
\hline 4 & $48 / 40$ & 5.5 & 8.0 & 7.28 & 1.6 & 23.3 & 6.5 \\
\hline \multicolumn{8}{|l|}{$1.5-\mathrm{h}$ arrest } \\
\hline 5 & $70 / 64$ & 4.4 & 14.4 & 7.09 & 1.3 & 20.1 & 20.0 \\
\hline 6 & $64 / 58$ & 11.2 & 11.2 & 7.24 & 3.9 & 3.2 & 12.5 \\
\hline 7 & $54 / 48$ & 7.7 & 10.6 & 7.25 & & 11.3 & 12.7 \\
\hline \multicolumn{8}{|l|}{2.0 -h arrest } \\
\hline 8 & $32 / 28$ & 5.9 & 20.0 & 7.11 & 1.4 & 5.5 & 8.0 \\
\hline 9 & $44 / 36$ & 9.0 & 9.4 & 7.34 & 9.9 & 7.1 & 14.6 \\
\hline 10 & $30 / 24$ & 4.5 & 19.3 & 7.16 & 2.4 & 3.1 & 21.1 \\
\hline
\end{tabular}

* Numbers representing the physiologic variables are those obtained at 1,2 , or $3 \mathrm{~h}$ of recovery. The therapeutic infusions were averaged over $3-4$ $\mathrm{h}$ of recovery. The animal numbers are not in order of experimental manipulation.

Table 2. Incidence and severity of ischemic neuronal damage in individual newborn dogs subjected to hypothermic circulatory arrest*

\begin{tabular}{clll}
\hline \multirow{2}{*}{ Animal } & \multicolumn{2}{c}{ Cerebral cortex } & Hippocampus \\
\cline { 2 - 3 } & Anterior & Posterior & \\
\hline 1.0-h arrest & & & \\
1 & 0 & 0 & 0 \\
2 & 0 & 0 & 0 \\
3 & 0 & 0 & 0 \\
4 & 0 & 0 & 0 \\
1.5-h arrest & & & 0 \\
5 & + & + & 0 \\
6 & + & ++ & \\
7 & ++ & ++ & + \\
2.0 -h arrest & & & + \\
$8 \dagger$ & ++++ & ++++ & 0 \\
9 & +++ & ++++ & +++ \\
\hline
\end{tabular}

* Symbols represent extent of brain damage:,$+<5 \%$ of neurons damaged;,$++ 5-25 \%$ of neurons damaged;,$+++ 26-50 \%$ of neurons damaged; ++++ , majority of neurons damaged.

+ Caudate $=++$.

mild hippocampal damage, focused predominantly upon the subiculum with relative sparing of the remainder of the pyramidal cell layer. In a single animal, mild ischemic neuronal damage was apparent in the caudate nuclei. All lesions were seen bilaterally and relatively symmetrically in the brain-damaged puppies. Acute hemorrhage within the choroid plexi of the lateral or 4th ventricles was seen in three of the six animals subjected to cardiac arrest for 1.5-2 $\mathrm{h}$; however, intraventricular or subarachnoid hemorrhage was not observed.

\section{DISCUSSION}

The investigations presented here demonstrate the feasibility of subjecting newborn dogs to hypothermic circulatory arrest of at least $2 \mathrm{~h}$ duration with successful cardiopulmonary resuscitation thereafter. In addition, the systemic physiologic and metabolic alterations that occur during hypothermia alone and during cardiac arrest and recovery had been well characterized. The findings indicate that puppies are capable of sustaining $1 \mathrm{~h}$ of hypothermic circulatory arrest without brain damage, with graded neuronal injury occurring at longer intervals of cardiac arrest. It remains to be determined whether or not the animals are capable of partial or complete functional recovery, as they

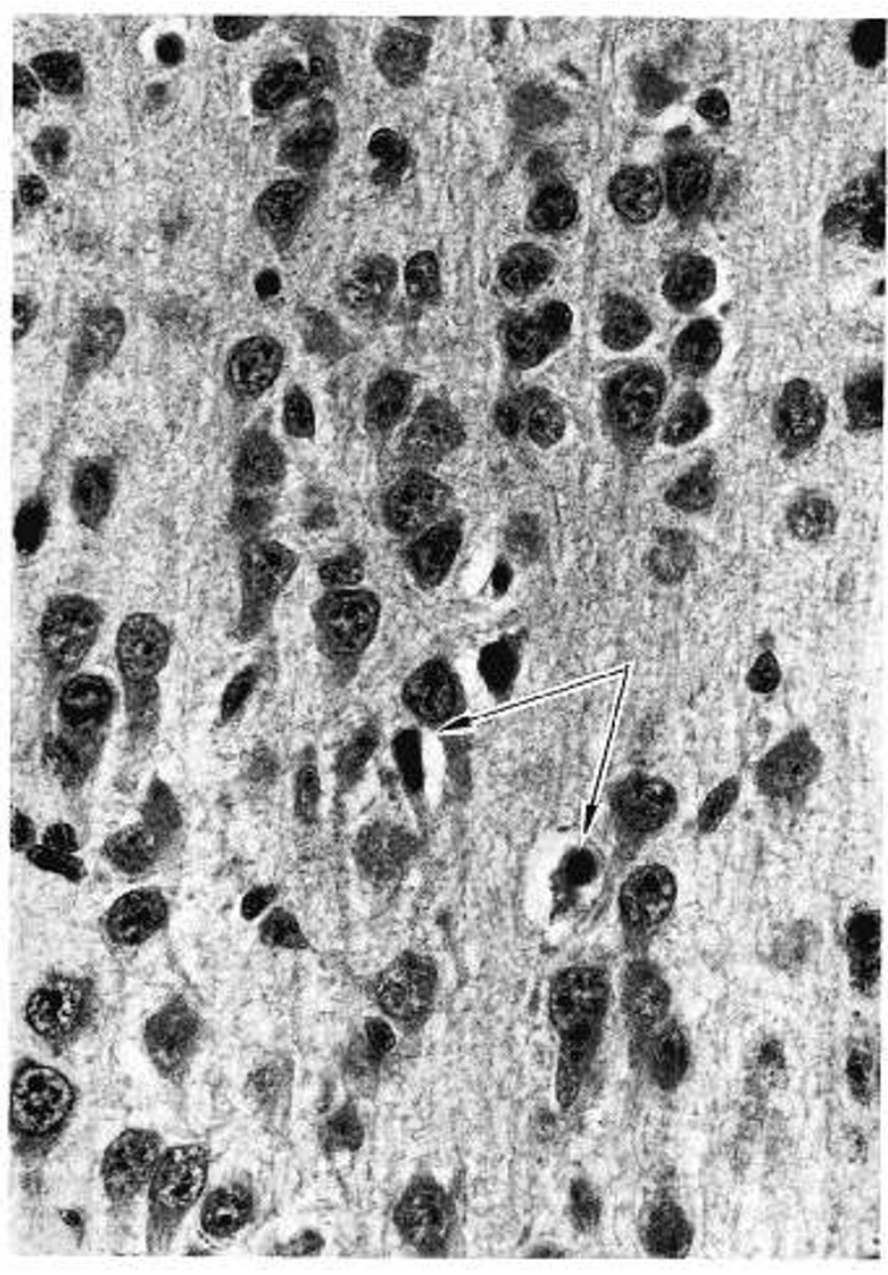

Fig. 4. High power view of cerebral cortex showing shrunken pyramidal neurons with dense pyknotic nuclei (arrows). (Hematoxylin and eosin; $520 \times$.)

continued to be mildly anesthetized and paralyzed until death at 3-4 h.

Studies conducted many years ago suggested a protective influence of hypothermia on hypoxic survival and on hypoxic-ischemic brain damage in immature animals (12-14). More recently, Young et al. (2) used an immature rat model of hypoxic- 

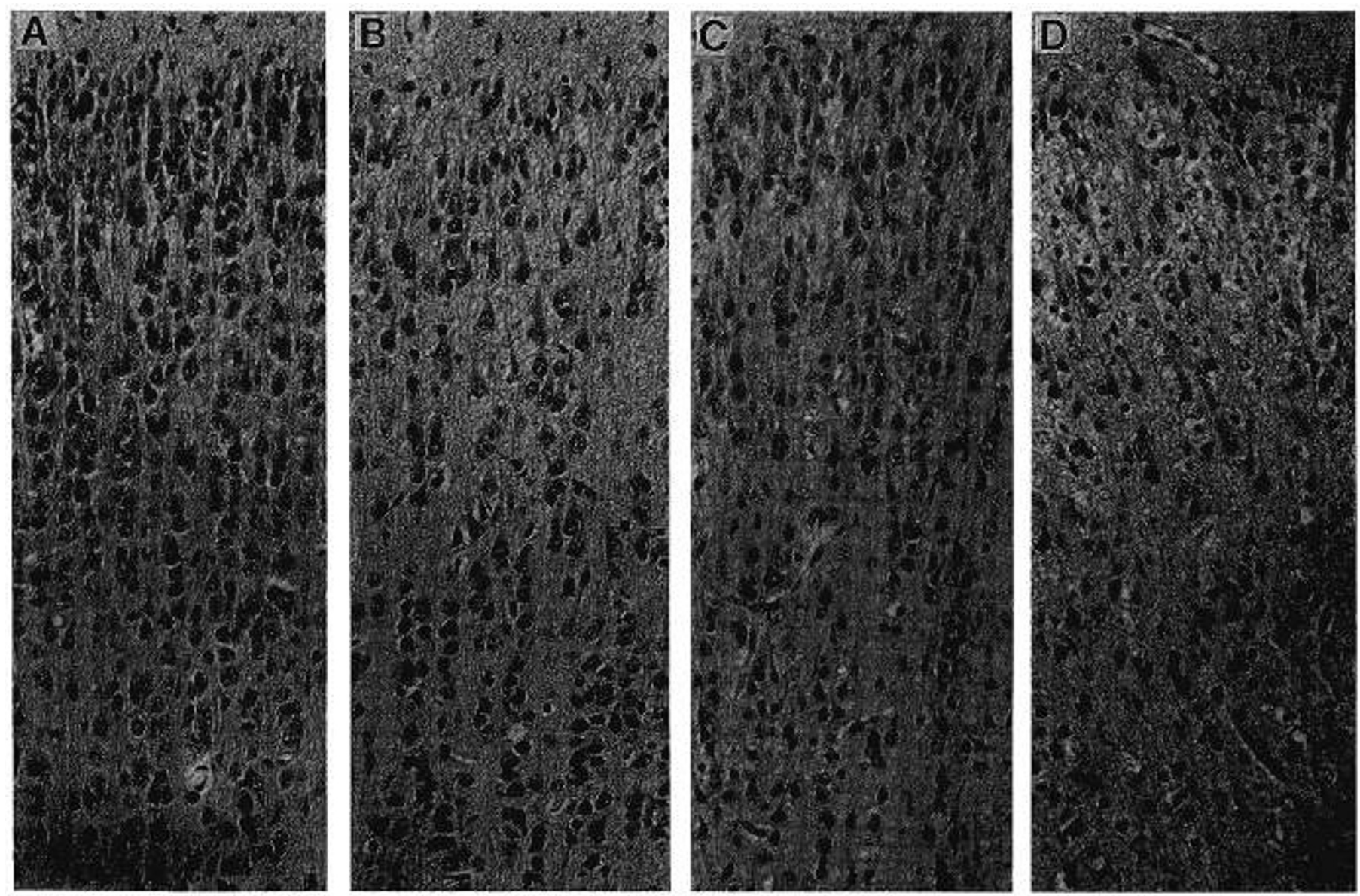

Fig. 5. Representative sections of cerebral cortex showing no $(A)$, mild $(B)$, moderate $(C)$, and severe $(D)$ damage with selective neuronal necrosis. In the damaged brains $(B$ and $C$ ), neuronal alterations are apparent, either localized on layers 3 and $5+6$ or scattered throughout the cerebral cortex. In severe damage $(D)$, neuronal necrosis is associated with rarefaction of the neuropile, suggesting early laminar necrosis. (Hematoxylin and $\operatorname{eosin} ; 200 \times$.).

ischemic brain damage (15) to examine the effect of hypothermia on the extent of tissue injury. Seven-d postnatal rats were subjected to unilateral common carotid artery occlusion followed by hypoxia with $8 \%$ oxygen for $3.5 \mathrm{~h}$. The extent of brain damage was far less extensive in those rat pups exposed to hypoxiaischemia at $29^{\circ} \mathrm{C}$ than in those exposed at $37^{\circ} \mathrm{C}$. Neuronal injury was nonexistent in animals exposed to hypoxia-ischemia at $21^{\circ} \mathrm{C}$. The investigators concluded that moderate hypothermia $\left(29^{\circ} \mathrm{C}\right)$ affords partial and profound hypothermia $\left(21^{\circ} \mathrm{C}\right)$ complete protection from perinatal hypoxic-ischemic brain damage.

Although our present study is the first to describe the early pathologic alterations that occur in the brains of immature animals after hypothermic circulatory arrest, several investigations have been conducted in adult animals, especially dogs. In this regard, neuropathologic studies have shown that brain damage may not occur for up to $90 \mathrm{~min}$ of hypothermic circulatory arrest in these mature animals $(1,3,4)$. The distribution of tissue injury was similar to that observed in newborn dogs (present study), specifically laminar necrosis of the deeper layers of the cerebral cortex with less frequent and less severe damage in other structures, including brainstem and cerebellum. It is surprising that adult dogs withstand hypothermic circulatory arrest of intervals comparable to those of newborn puppies with little or no brain damage despite their higher rates of cerebral oxidative metabolism at both normothermia and hypothermia (16-18).

It is noteworthy that the reaction to injury of the newborn dog brain was relatively advanced even at $3-4 \mathrm{~h}$ of recovery from hypothermic circulatory arrest. Thus, homogenizing cell change, with eosinophilic cytoplasm and pyknotic or karyorrhexic nuclei, was the predominant stage in the ischemic process (15). The brunt of tissue injury was focused on the cerebral cortex, in which selective neuronal necrosis, when severe, occurred in a laminar distribution, a pattern characteristic of both adult animals and humans sustaining global cerebral ischemia (19). Tissue injury was not accentuated at the depths of cortical sulci, again in keeping with an insult to brain characterized by total ischemia secondary to cardiac arrest rather than by partial ischemia arising from systemic hypotension.

Mild ischemic injury to the subiculum of the hippocampus occurred in two of three newborn dogs subjected to $2 \mathrm{~h}$ of hypothermic circulatory arrest. Subicular necrosis with sparing of the remainder of the pyramidal cell layer in the hippocampus also has been observed in human infants subjected to cerebral hypoxia-ischemia, the lesion usually occurring in combination with injury to selected regions of the brainstem (ponto-subicular necrosis) (20-23). Relatively isolated brainstem damage has been described in asphyxiated newborn infants (24-26), as well as in children and adults sustaining severe systemic hypotension or cardiac arrest (27-29), and is the hallmark of the brain damage occurring in fetal monkeys subjected to acute total asphyxiation (30). The absence of major hippocampal or brainstem damage in newborn dogs recovering from hypothermic circulatory arrest may reside in a reduced vulnerability of these structures afforded to them by hypothermia. Alternatively, the reaction to injury of these regions of brain may be delayed beyond the 3-4 h of recovery allowed to the puppies; such "delayed neuronal necrosis" is a prominent feature of the hippocampus in adult animals subjected to cerebral ischemia $(31,32)$.

The mechanism of the protective effect of hypothermia on brain tissue subjected to ischemic stress relates to a reduction in 
cerebral energy demands that are relatively proportionate to a reduction in cerebral blood flow (33-36). Of necessity, a mismatch occurs between blood flow and metabolism during hypothermic circulatory arrest, because in the absence of cerebral perfusion, metabolism must continue at a basal rate to maintain ion gradients and structural integrity. Basal metabolism would be expected to continue for extended intervals in immature animals, owing to physiologically low rates of cerebral energy use combined with high endogenous stores of carbohydrates (glucose and glycogen), which serve as organic fuels for anaerobic glycolysis and energy production $(37,38)$. Indeed, ATP concentrations in the brains of poikilothermic animals (e.g. turtles, frogs, fish) are not exhausted for many hours of total cerebral ischemia (39). Therefore, the lower the cerebral metabolic rate of an animal at normothermia, the greater the hypoxic-ischemic resistance promoted by hypothermia. However, the observation does not explain why adult dogs tolerate intervals of hypothermic circulatory arrest comparable to those of newborn dogs without sustaining brain damage. Studies are in progress to ascertain the extent to which oxidative metabolism in newborn dog brain is disturbed during and after the prolonged ischemia produced by hypothermic cardiac arrest.

Measurement of several physiologic variables before, during, and after hypothermic circulatory arrest indicated that major alterations in systemic homeostasis occurred in the recovery period. Among the disturbances were an early hyperglycemia, a progressive lactacidemia with associated metabolic acidosis, and a secondary systemic hypotension, all of which were apparent in those puppies sustaining 1.5 and $2 \mathrm{~h}$ of cardiac arrest. The data presented in Table 1 suggest that these postischemic systemic alterations did not accentuate the brain tissue injury seen in the majority of the puppies, inasmuch as comparable disturbances in plasma glucose, blood lactate, $\mathrm{pHa}$, and blood pressure occurred in the damaged and undamaged animals. The two exceptions were newborn dogs nos. 8 and 10, in which hypoglycemia, lactacidosis, and hypotension during recovery may have contributed to the widespread neuronal changes seen in these severely brain-damaged animals.

It must be emphasized that the measurements of plasma glucose and blood lactate at the terminus of cardiac arrest should be interpreted with caution, inasmuch as the blood specimens were collected at a time when the animals were pulseless and without blood pressure. It is likely that little or no diffusion of glucose into and lactate from the ischemic tissues occurred during the period of circulatory arrest. The prompt increase in plasma glucose after resuscitation undoubtedly reflected transport of the substrate from hepatic stores into blood after stimulation of glucose production by the endogenous secretion and exogenous administration of epinephrine. The lactacidemia that also occurred during early recovery presumably resulted from diffusion of lactate from previously ischemic tissues into the blood stream once the systemic circulation was restored.

Notable technical differences exist between the manner of inducing hypothermic circulatory arrest in newborn dogs and the operative procedure in human infants. First, core cooling to $18-20^{\circ} \mathrm{C}$ in humans is accomplished using both surface cooling and cardiopulmonary bypass with chilled, heparinized blood. Second, humans typically are hemodiluted to a hematocrit of 25 , hopefully to prevent or minimize intra- and postoperative thrombus formation and embolization to vital organs. Thirdly, infants may receive thiopental sodium (6 or more $\mathrm{mg} / \mathrm{kg}$ ) immediately before cardiac arrest in an attempt to reduce cerebral metabolism to a rate below that accomplished with hypothermia alone, thereby promoting even greater protection to the brain during the phase of total cerebral ischemia. Cardiopulmonary bypass would be technically difficult, if not impossible, in newborn dogs (body wt $=350-500 \mathrm{~g}$ ), whereas hemodilution and augmented barbiturate anesthesia are variables that can be objectively investigated in the newborn dog model of hypothermic circulatory arrest to determine their ability to retard the incidence and extent of ischemic brain damage. Animal studies also will allow the assessment of newer modalities of therapeutic intervention to prevent brain damage including calcium channel blockers, excitatory amino acid receptor antagonists, and free radical inhibitors or scavengers (40-43).

In summary, our investigation documents the ability of newborn dogs to be subjected to and successfully resuscitated from hypothermic circulatory arrest of intervals lasting up to $2 \mathrm{~h}$. Furthermore, studies in progress indicate that such puppies are capable of at least partial functional recovery, including weaning from anesthesia and artificial ventilation. Thereafter, the animals exhibit sustained respiration, sucking and crying activity, and spontaneous movements of all extremities. The animal model should prove useful in further investigations to uncover those pathophysiologic mechanisms responsible for ischemic brain damage. In addition, treatment with drugs thought to protect the brain from ischemic injury can be accomplished to ascertain their efficacy in the clinical setting.

Acknowledgments. The authors thank Robert M. Brucklacher, Melanie A. Christensen, and Cathy Housman for their expert technical assistance.

\section{REFERENCES}

1. Treasure T, Naftel DC, Conger KA, Garcia JH, Kirklin JW, Blackstone EH 1983 The effect of hypothermic circulatory arrest time on cerebral function, morphology and biochemistry. J Thorac Cardiovasc Surg 86:761-770

2. Young RSK, Olenginski TP, Yagel SK, Towfighi J 1982 The effect of graded hypothermia on hypoxic-ischemic brain damage: a neuropathologic study in the neonatal rat. Stroke 14:929-934

3. Molina JE, Einzig S, Mastri AR, Bianco RW, Marks JA, Rasmussen TM, Clack RM 1984 Brain damage in profound hypothermia: perfusion versus circulatory arrest. J Thorac Cardiovasc Surg 87:596-604

4. O'Connor JV, Wilding T, Farmer P, Sher J, Ergin MA, Griepp RB 1986 The protective effect of profound hypothermia on the canine central nervous system during one hour of circulatory arrest. Ann Thorac Surg 41:225-259

5. Hickey PR, Anderson NP 1987 Deep hypothermic circulatory arrest: a review of pathophysiology and clinical experience as a basis for anesthetic management. J Cardiothorac Anes 1:137-155

6. Stevenson JG, Stone EF, Dillard DH 1974 Intellectual development of children subjected to prolonged circulatory arrest during hypothermic open heart surgery in infancy. Circulation 49:54-59

7. Dickinson DF, Sambrooks JE 1979 Intellectual performance in children after circulatory arrest with profound hypothermia in infancy. Arch Dis Child 54:1-6

8. Wells FC, Coghill S, Caplan HL 1983 Duration of circulatory arrest does influence the psychological development of children after cardiac operations in early life. J Thorac Cardiovasc Surg 86:823-831

9. Brunberg JA, Reilly EL, Doty DB 1974 Central nervous system consequences in infants of cardiac surgery using deep hypothermia and circulatory arrest. J Cardiovasc Surg 49:60-68

10. Ferry PC 1987 Neurologic sequelae of cardiac surgery in children. Am J Dis Child 141:309-312

11. Siesjö BK 1978 Brain Energy Metabolism. Wiley, Chichester, England, pp 324-339

12. Mott JC 1961 The ability of young mammals to withstand total oxygen lack. Br Med Bull 17:144-148

13. Daniel SS, Dawes GS, James LS 1966 Hypothermia and the resuscitation of the asphyxiated fetal rhesus monkeys. J Pediatr 68:45-53

14. Heideger PM, Miller FS, Millar JA 1970 Cerebral and cardiac enzymatic activity and tolerance to asphyxia during maturation in the rabbit. J Physiol 206:25-40

15. Rice JE, Vannucci RC, Brierley JB 1981 The influence of immaturity on hypoxic-ischemic brain damage in the rat. Ann Neurol 9:131-141

16. Hernandez MJ, Brennan RW, Vannucci RC, Bowman GS 1978 Cerebral blood flow and oxygen consumption in the newborn dog. Am J Physiol 234:R209-R215

17. Mujsce DJ, Christensen MA, Vannucci RC 1989 Regional cerebral blood flow and glucose utilization during hypoglycemia in newborn dogs. Am J Physiol 256:H1659-H1666

18. Palmer C, Vannucci RC, Christensen MA, Brucklacher RM 1989 Regional cerebral blood flow and glucose utilization during hypothermia in newborn dogs. Anesthesiology 71:730-737

19. Brierley JB, Graham DL 1984 Hypoxia and vascular disorders of the central nervous system. In: Adams JH, Corsellis JAN, Duchen LW (eds) Greenfield's Neuropathology. Wiley, New York, pp 125-208

20. Friede RL 1972 Pontosubicular lesions in perinatal anoxia. Arch Pathol Lab Med 94:343-348

21. Ahdab-Barmada M, Moossy J, Painter M 1980 Pontosubicular necrosis and hyperoxia. Pediatrics 66:840-847 
22. Rorke LB 1982 Pathology of Perinatal Brain Injury. Raven Press, New York pp $118-121$

23. Bozóky B, Cara D, Kertész E 1984 Autopsy study of cerebral complications of congenital heart disease and cardiac surgery. J Neurol 231:153-161

24. Schneider H, Ballowitz L, Schachinger H, Hanefeld F, Dröszus J-U 1975 Anoxic encephalopathy with predominant involvement of basal ganglia, brainstem and spinal cord in the perinatal period. Acta Neuropathol. 32:287298

25. Leech RW, Alvord EC 1977 Anoxic-ischemic encephalopathy in the human neonatal period: the significance of brainstem involvement. Arch Neurol 34:109- 113

26. Roland EH, Hill A, Norman MG, Flodmark O, MacNab AJ 1988 Selective brainstem injury in an asphyxiated newborn. Ann Neurol 23:89-92

27. Brierley JB 1966 The influence of brain swelling, age and hypotension upon the pattern of cerebral damage in hypoxia. In: Luthy F, Bischoff A (eds) Proceedings of the Fifth International Congress of Neuropathology. Excerpta Medica, Amsterdam, pp 21-28

28. Jurgensen JC, Towfighi J, Brennan RW, Jeffreys WH 1983 Symmetric brainstem necrosis in an adult following hypotension: an arterial end-zone infarct? Stroke 14:967-970

29. Révész T, Geddes JF 1988 Symmetrical columnar necrosis of the basal ganglia and brainstem in an adult following cardiac arrest. Clin Neuropathol 7:294298

30. Ranck JB, Windle WF 1959 Brain damage in the monkey, Macaca mulatta, by asphxyia neonatorum. Exp Neurol 1:130-154

31. Kirino T 1982 Delayed neuronal death in the gerbil hippocampus following ischemia. Brain Res 239:57-69

32. Pulsinelli WA, Brierley JB, Plum F 1982 Temporal profile of neuronal damage in a model of transient forebrain ischemia. Ann Neurol 11:491-498

33. Perna AM, Gardner TJ, Tabaddor K, Brawley RK, Gott VL 1973 Cerebral metabolism and blood flow after circulatory arrest during deep hypothermia. Ann Surg 178:95-101

34. Lafferty JJ, Keykhah MM, Shapiro HM, Van Horn K, Behar MG 1978 Cerebral hypometabolism obtained with deep pentobarbital anesthesia and hypothermia $\left(30^{\circ} \mathrm{C}\right)$. Anesthesiology 49:159-164

35. Astrup J, Sørensen PM, Sørensen HR 1981 Inhibition of cerebral oxygen and glucose consumption in the dog by hypothermia, pentobarbital and lidocaine. Anesthesiology 55:263-268

36. Steen PA, Newberg L, Milde JH, Michenfelder JD 1983 Hypothermia and barbiturates: individual and combined effects on canine cerebral oxygen consumption. Anesthesiology 58:527-532

37. Vannucci RC, Plum F 1975 Pathophysiology of perinatal cerebral hypoxiaischemia. In: Gaull E (ed) Biology of Brain Dysfunction. Plenum Press, New York, pp 1-45

38. Vannucci RC 1982 Vulnerability of the immature brain to hypoxia-ischemia. In: Cold Spring Harbor Symposium, Banbury Report II: Environmental Effects of Maturation. Cold Spring Harbor Laboratory, Cold Spring Harbor, NY, pp 2691-2698

39. McDougal DB, Holowach J, Howe MC, Jones EM, Thomas CA 1968 The effect of anoxia upon energy sources and selected metabolic intermediates in the brain of fish, frog and turtle. J Neurochem 15:577-588

40. Hossman K-A 1982 Treatment of experimental cerebral ischemia. J Cereb Blood Flow Metab. 2:275-297

41. Raichle ME 1983 The pathophysiology of brain ischemia. Ann Neurol 13:210

42. Rothman SM, Olney JW 1986 Glutamate and the pathophysiology of hypoxicischemic brain damage. Ann Neurol 19:105-111

43. Siesjö BK, Bengtsson F 1989 Calcium fluxes, calcium antagonists, and calciumrelated pathology in brain ischemia, hypoglycemia, and spreading depression: a unifying hypothesis. J Cereb Blood Flow Metab 9:127-140 